\title{
Is there a difference in 25-hydroxyvitamin D levels between female university students with and without joint hypermobility?
}

\author{
Filiz Tuna $^{1} \odot$, Hande Özdemir ${ }^{2}$, Derya Demirbağ Kabayel²๑, Zeynep Banu Doğanlar ${ }^{3} \odot$ \\ ${ }^{1}$ Department of Physical Therapy and Rehabilitation, Trakya University School of Health Sciences, Edirne, Turkey \\ ${ }^{2}$ Department of Physical Therapy and Rehabilitation, Trakya University School of Medicine, Edirne, Turkey \\ ${ }^{3}$ Department of Medical Biology, Trakya University School of Medicine, Edirne, Turkey
}

DOI: $10.18621 /$ eurj.411056

\begin{abstract}
Objectives: Individuals with joint hypermobility $(\mathrm{JH})$ constitute a sensitive group with regard to musculoskeletal problems. This study aimed to investigate whether females with generalized joint hypermobility $(\mathrm{GJH})$ are at risk of hypovitaminosis D compared with non-GJH female participants and whether there is a relationship between vitamin D levels, Beighton score and musculoskeletal complaints.

Methods: In this cross-sectional, descriptive and case-control study, 76 female participants aged 18-25 years were included. The Beighton score with a cut-off of 4/9 was applied for defining GJH. In addition, serum biochemical (the enzymatic colorimetric method) and hormonal (the electrochemiluminescence method) parameters were evaluated.

Results: The mean serum 25-hydroxyvitamin D (25[OH]D) levels of GJH $(n=38)$ and non-GJH $(n=38)$ groups were $15.70 \pm 7.96 \mathrm{ng} / \mathrm{mL}$ and $16.80 \pm 5.45 \mathrm{ng} / \mathrm{mL}$, respectively. There was no statistically significant difference between the groups in terms of biochemical and hormonal parameters. We found vitamin $\mathrm{D}$ deficiency in $89.5 \%$ of participants with GJH, and $84.2 \%$ of controls. There was no correlation between vitamin D, Brighton criteria, and musculoskeletal complaints.

Conclusion: The female participants with GJH showed similar frequency of musculoskeletal complaints and similar low level of $25(\mathrm{OH}) \mathrm{D}$ in relation to controls.
\end{abstract}

Keywords: female, joint hypermobility, musculoskeletal complaints, 25-hydroxyvitamin D deficiency

Received: March 30, 2018; Accepted: May 19, 2018; Published Online: September 15, 2018

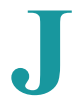
oint hypermobility or laxity is having a range of motion beyond the limits of normal joint. It can affect one or more joints. Beighton scoring (BS), where in nine joints are evaluated, is used to define $\mathrm{JH}$ and BS 4-6/9 is reported as generalized joint hypermobility (GJH) [1, 2]. Hypermobility brings with it many problems as musculoskeletal or systemic manifestations. Musculoskeletal manifestations are trau- mas, degenerative joint and bone diseases, disturbed proprioception, muscle weakness and musculoskeletal traits. Systemic manifestations are cardiovascular involvements, skin, mucosae, fascia involvement, and nervous system involvement [2]. These manifestations were included easily under the umbrella named hypermobility syndrome or hypermobile Ehlers-Danlos syndrome (hEDS) with Brighton criteria until the 2017

Address for correspondence: Filiz Tuna, MD., Trakya University School of Health Sciences, Department of Physical Therapy and Rehabilitation, Edirne, Turkey 
International Classification of EDS that were based on strict criteria [3].

According to updated classification hEDS is a connective tissue disorder simultaneously comprised; 1) Beighton score $\geq 5 / 9,2$ ) At least two of of feature A (at least 5 meets of a 12 systemic features of a connective tissue), feature $\mathrm{B}$ (positive family history) and feature $\mathrm{C}$ (at least one existence of three musculoskeletal complications), and 3) Exclusion of extraordinary skin fragility, further connective tissue disorders, and another diseases with JH. However, feature B was accepted enough for the diagnosis [3].

Although Vitamin D is a hormone that is essential for functioning of muscles, as well as bone mineralization [4], until now, no study has reported vitamin D levels in GJH and its correlation with musculoskeletal complaints. Hypermobile EDS with GJH is reported as risk for chronic pain, fatigue [5], low bone density, osteoporosis, and fractures [6, 7]. While management suggestions include considering 25-hydroxyvitamin $\mathrm{D}(25[\mathrm{OH}] \mathrm{D})$ deficiency, there is no enough data on levels of $25(\mathrm{OH}) \mathrm{D}$ in EDS groups as well as GJH [8-11]. Considering the possibility that individuals with GJH differ from controls in mean of level of 25(OH)D and some biochemical parameters (sodium, potassium, chlorine, alkaline phosphatase, calcium, phosphorus, magnesium, iron, and iron binding capacity levels) we aimed to evaluate them and comprise with controls.

\section{METHODS}

\section{Patients}

For the aims of this study, we selected females with definition of GJH according to the Beighton scoring, aged between 18-25 years. Participants were selected from a total of 221 female students from the Health Sciences Faculty of Trakya University (Edirne, Turkey). A group of students with Beighton score $\leq$ $3 / 9$ and no any genetic disorder, chronic drug use and chronic disease of locomotor system was selected as control. All participant were selected from the same sources. Controls were matched by age and sex with individuals with GJH. Participants with a Beighton score of $\geq 4 / 9$ were included in the GJH group and those with a score $\leq 3 / 9$ were included in the control group (non-GJH) [12]. Exclusion criteria were male sex, drug use, and the presence of a known disease in both groups (Figure 1). Based on the mean 25(OH)D vitamin level 26.3 in the control group [13] and minimum difference between groups of $25 \%$, an $\alpha$ error of $5 \%$, SD of $10 \%$, and power $80 \%$ we defined a sample of 38 participants for each group. This observational, cross-sectional (between February 2017 and July 2017), controlled, quantitative study was approved by the Ethics Committee of the Trakya University Medical Faculty (TÜTF-BAEK-2016/105) and written informed consent was obtained from each participants.

Edirne is city in the Marmara Region of Turkey, latitudes $40^{\circ} 30-42^{\circ} 00$ North 1 and $26^{\circ} 00-27^{\circ} 00$ East. Average maximum temperatures range between $6.5^{\circ} \mathrm{C}$ in winter and $31.7^{\circ} \mathrm{C}$ in summer, with annual average of $19.6^{\circ} \mathrm{C}$ [14].

\section{Clinical Evaluation}

A total of 221 female students from Health Science Faculty of Trakya University (Edirne, Turkey) underwent an initial clinical interview and Beighton scoring. Beighton scoring was performed by evaluating nine joints and the following items:

I- Placement of hands flat on the floor without bending the knees

II- Hyperextension of the elbow to $\geq 10^{\circ}$

III- Hyperextension of the knee to $\geq 10^{\circ}$

IV-Opposition of the thumb to the volar aspect of the ipsilateral forearm

V- Passive dorsiflexion of the fifth metacarpophalangeal joint to $\geq 90^{\circ}$ [15]. During physical examination, we investigated the presence of features used in the diagnosis of hEDS according to the 2017 International Classification of EDS [3]. Data collected included age, sex, height, weight, BMI, clothing style, and history of musculoskeletal complaint. To evaluate history of the musculoskeletal complaint, participants were questioned aboutthe joint pain, widespread musculoskeletal pain and soft tissue injuries. Clothing style of the participants was registered by researchers based on their observations as veiled or not.

\section{Laboratory Evaluation}

After 10-12 h fasting, venous blood samples fromthe antecubital area were taken from all participants between 08.30 and 9.00 in the morning 


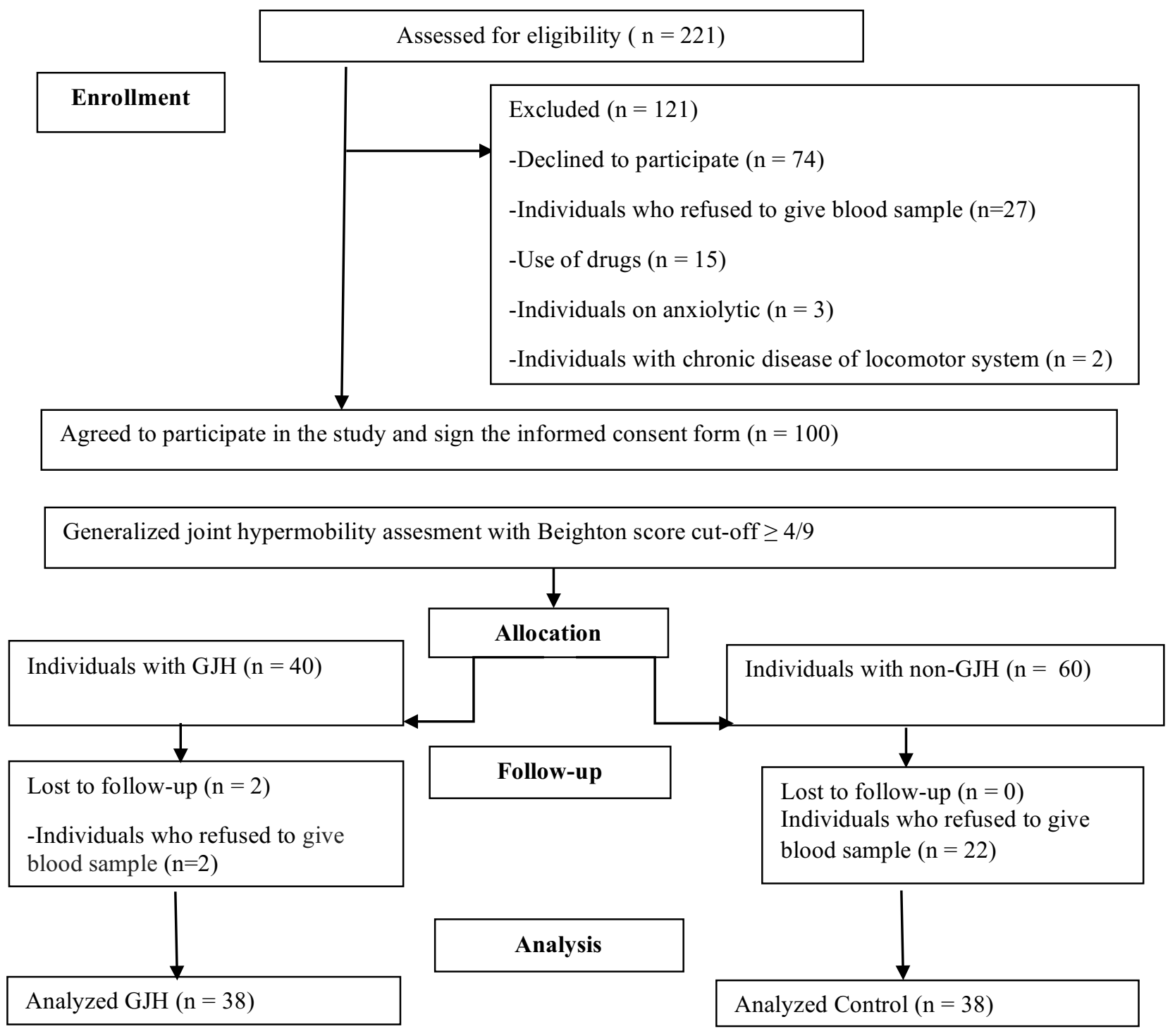

Figure 1. Flow diagram of the progress.

from April 2017 to May 2017. Serum sodium, potassium, chlorine, alkaline phosphatase, calcium, phosphorus, magnesium, iron, and iron binding capacity levels were measured using the enzymatic colorimetric method (Beckman Coulter AU 5800), and serum $25(\mathrm{OH}) \mathrm{D}$, folic acid, and ferritin levels were evaluated using the electrochemiluminescence method (Beckman Coulter UniCelDxI 600). 25(OH)D levels of participants were classified according to the Endocrine Society asdeficiency $(<20 \mathrm{ng} / \mathrm{mL})$, insufficiency (21-29 $\mathrm{ng} / \mathrm{mL})$, normallevels (30-39 $\mathrm{ng} / \mathrm{mL}$ ), and preferred levels (40-60 ng/mL) [16].

\section{Statistical Analysis}

Statistical evaluation was performed by the IBM SPSS version 20.0 statistics software package (IBM Corporation, Armonk, NY, USA). Descriptive variables were reported within groups according to frequency, means, standard deviation, and percentages. Normal distribution were evaluated by the Shapiro-Wilk test. T test was used for normally distributed data. Spearman's rho correlation analysis test was used to assess correlations between variables. A $p$ value of $<0.05$ was considered statistically significant. 
Table 1. Characteristics of participants with GJH and controls

\begin{tabular}{|c|c|c|c|c|}
\hline & Groups & $\mathbf{n}$ & Mean \pm SD & $p$ value \\
\hline \multirow[t]{3}{*}{ Age, year } & GJH & 38 & $19.87 \pm 1.45$ & 0.239 \\
\hline & Control & 38 & $20.26 \pm 1.44$ & \\
\hline & Total & 76 & $20.07 \pm 1.45$ & \\
\hline \multirow[t]{3}{*}{ Height, m } & GJH & 38 & $1.65 \pm 0.05$ & 0.464 \\
\hline & Control & 38 & $1.64 \pm 0.04$ & \\
\hline & Total & 76 & $1.64 \pm 0.05$ & \\
\hline \multirow[t]{3}{*}{ Weight, kg } & GJH & 38 & $56.31 \pm 6.29$ & 0.643 \\
\hline & Control & 38 & $57.05 \pm 7.45$ & \\
\hline & Total & 76 & $56.68 \pm 6.86$ & \\
\hline \multirow[t]{3}{*}{ BMI, $\mathrm{kg} / \mathrm{m}^{2}$} & GJH & 38 & $20.63 \pm 1.75$ & 0.304 \\
\hline & Control & 38 & $21.14 \pm 2.44$ & \\
\hline & Total & 76 & $20.88 \pm 2.13$ & \\
\hline \multirow{3}{*}{ Veiled clothing style, $\%$} & GJH & 9 & 23.7 & 0.079 \\
\hline & Control & 7 & 18.4 & \\
\hline & Total & 16 & 21.1 & \\
\hline \multirow{3}{*}{ History of musculoskeletal complaint, \% } & GJH & 14 & 43.8 & 0.486 \\
\hline & Control & 18 & 56.3 & \\
\hline & Total & 32 & 42.1 & \\
\hline \multirow[t]{3}{*}{25 (OH)D level, ng/ml } & GJH & 38 & $15.73 \pm 7.97$ & 0.496 \\
\hline & Control & 38 & $16.80 \pm 5.46$ & \\
\hline & Total & 76 & $16.26 \pm 6.81$ & \\
\hline
\end{tabular}

$\mathrm{GJH}=$ generalized joint hypermobility, $\mathrm{BMI}=$ body mass index

\section{RESULTS}

Complete laboratory data were obtained for 76 female participants, of whom 38 had GJH and 38 did not. Total Beighton score range were 0-9/9. The average ages of GJH and control groups were $19.87 \pm$ 1.45 and $20.26 \pm 1.44$ years, respectively. Participants'

Table 2. Correlations of parameters with statistically significance

\begin{tabular}{llcc}
\hline & & r & $\boldsymbol{p}$ value \\
\hline Age & Chlorine & -0.277 & 0.020 \\
& Phosphorus & 0.287 & 0.014 \\
& $\begin{array}{l}\text { Hyperextension of } \\
\text { right elbow }\end{array}$ & -0.229 & 0.046 \\
& $\begin{array}{l}\text { Hyperextension of } \\
\text { right knee }\end{array}$ & -0.264 & 0.021 \\
& Hyperextension of & -0.252 & 0.028 \\
Weight & left knee & 0.267 & 0.023 \\
& Calcium & 0.485 & $<0.001$ \\
Height & 0.847 & $<0.001$ \\
levels & BMI & 0.303 & 0.008 \\
& Weight (kg) & 0.265 & 0.022 \\
& Potassium & -0.340 & 0.003 \\
& $\begin{array}{l}\text { Hyperextension of } \\
\text { right elbow }\end{array}$ & -0.244 & 0.034 \\
& Hyperextension of & & \\
\hline
\end{tabular}

age, height, weight, BMI, clothing style, and history of musculoskeletal pain parameters were normally distributed. The mean serum 25(OH)D levels of GJH and control groups were found no statistically different (Table 1). Laboratory data of sodium, potassium, chlorine, alkaline phosphatase, calcium, phosphorus, magnesium, and iron, were obtained for 73 participants, of whom 38 had GJH and 35 did not. There was no statistically significant difference between the GJH and control groups with respect to the biochemical and hormonal levels. Significant positive correlation was found between weight and 25(OH)D levels (Table 2). Neither in the GJH nor in the control group hEDS was identified.

Distribution of participants according to $25(\mathrm{OH}) \mathrm{D}$ calassifications among the GJH and control groups was showed in Table 3. Only one of participants had preferred level of vitamin D.No correlation was found between the Beighton scores, musculoskeletal manifestations, and serum 25(OH)D levels. No correlation was found between the clinical parameters (Beighton scoring parameters) of participants with GJH and 25(OH)D levels, except for a statistically significant negative correlation between the $25(\mathrm{OH}) \mathrm{D}$ levels and the hyperextension of right and left elbow (Table 2). 
Table 3. Distribution of $25(\mathrm{OH}) \mathrm{D}$ classifications among the groups

\begin{tabular}{llccc}
\hline & & \multicolumn{3}{c}{ n (\% within groups) } \\
\cline { 3 - 5 } & & GJH & Control & Total \\
\hline $\mathbf{2 5}(\mathbf{O H}) \mathbf{D}$ & Deficiency & $34(89.5)$ & $32(84.2)$ & $66(86.8)$ \\
classification & Insufficiency & $2(5.3)$ & $4(10.5)$ & $6(7.9)$ \\
& Normal & $1(2.6)$ & $2(5.3)$ & $3(3.9)$ \\
& Preferred & $1(2.6)$ & $0(0.0)$ & $1(1.3)$ \\
Total & & $38(100)$ & $38(100)$ & $76(100)$ \\
\hline
\end{tabular}

$\mathrm{GJH}=$ generalized joint hypermobility

\section{DISCUSSION}

Present study shows that mean 25(OH)D levels are low, but not statistically different in females with GJH. We also found no statistically significant association between Beighton scoring and neitherhistory of musculoskeletal complaint nor $25(\mathrm{OH}) \mathrm{D}$ levels. While $\mathrm{GJH}$ is widely known as predisposing to musculoskeletal pain, neither vitamin D deficiency nor insufficiency is not sufficiently researched in this population. Significant positive correlation was found between weight, BMI and $25(\mathrm{OH}) \mathrm{D}$ levels. These results are not consistent with previous studies reporting negative correlation between BMI and vitamin D in healthy adults [17]. This wasprobably due to both groups having normal mean BMI.

The lack of association between 25(OH)D levels and musculoskeletal complaints was probably because of both groups having levels below normal limits. These results are uniform with other studies that also reported no association between these variables. In retrospective multicenter study on patients who applied to physical medicine and rehabilitation outpatient clinics with non-specific muscle pain, vitamin $\mathrm{D}$ deficiency was detected in $70.9 \%$ of patients (without information about whether patients are hypermobile or not). However, vitamin D deficiency in this population was reported not associated with the severity and duration of pain [18]. Hypermobility, vitamin D deficiency, and female sex are risk factors for idiopathic musculoskeletal pain [11]. Of these, hypermobility and female sex are structural unchanging factors. However, it is possible to misdiagnosed musculoskeletal pain associated with vitamin $\mathrm{D}$ deficiency as a pain syndrome associated with joint laxity or vice versa. There are limited number of publications on the role of $25(\mathrm{OH}) \mathrm{D}$ in hEDS, defined by the Brighton criteria, where GJH and various symptoms as joint pain are questioned together $[6,9,19,20]$. Some publications suggest that vitamin $D$ should be observed in painful individuals with hEDS $[9,20]$. We found similar serum 25(OH)D levels between the groups and deficiency was found in $89.5 \%$ of participants with $\mathrm{GJH}$, and $84.2 \%$ of controls. These findings are consistent with low vitamin D levels in eight of 14 cases with vascular type EDS with mean age of $37 \pm 16$ years [21]. Vitamin D levels $<30 \mathrm{ng} / \mathrm{mL}$ were reported to be similar in classical and hypermobility type EDS (86\%) and control (82\%) groups with a mean age of $40.3 \pm$ 5.9 years. Mean serum 25(OH)D levels of individuals with classical or hypermobility type EDS have been reported as $20.2 \pm 12.9 \mathrm{ng} / \mathrm{mL}$ [6].

The participants with GJH showed no higher frequency of musculoskeletal complaints in relation to control participants, refusing the profile waited for this population, according to the literature. It was probably due to $25(\mathrm{OH}) \mathrm{D}$ in both groups below the recommended levels.

\section{Limitations}

A potential limitation of this study was limited number of participants. Current study did not include questionnaires interesting in socioeconomic status and vitamin D intake in the diet. In addition, our study was mainly female student-based and the need to establish knowledge on GJH and hEDS require studies with large population. 


\section{CONCLUSION}

The female participants with GJH showed similar frequency of musculoskeletal complaints and low $25(\mathrm{OH}) \mathrm{D}$ levels in relation to controls. The frequency of deficiency and insufficiency of 25(OH)D in current study is parallel to studies, reporting a high frequency of vitamin $\mathrm{D}$ below normal limits, even in places with plenty sunlight.

\section{Conflict of interest}

The authors disclosed no conflict of interest during the preparation or publication of this manuscript.

\section{Financing}

This study was supported by the Trakya University Research Project Foundation (Project Number: TÜBAP-2017/08), Edirne, Turkey.

\section{Acknowledgements}

We are particularly grateful to all individuals who volunteered to participate in this study. We also thank Prof. Dr. Necdet Süt, who performed the statistical analysis of the study.

\section{REFERENCES}

[1] Beighton P, De Paepe A, Steinmann B, Tsipouras P, Wenstrup RJ. Ehlers-Danlos syndromes: revised nosology. Villefranche, 1997. Ehlers-Danlos National Foundation (USA) and EhlersDanlos Support Group (UK). Am J Med Genet 1988;77:31-7.

[2] Castori M, Tinkle B, Levy H, Grahame R, Malfait F, Hakim A. A framework for the classification of joint hypermobility and related conditions. Am J Med Genet C Semin Med Genet C Semin Med Genet 2017; 175:148-57.

[3] Malfait F, Francomano C, Byers P, Belmont J, Berglund B, Black J, et al. The 2017 international classification of the EhlersDanlos syndromes. Am J Med Genet 2017;175:8-26.

[4] Wintermeyer E, Ihle C, Ehnert S, Stöckle U, Ochs G, de Zwart $\mathrm{P}$, et al. Crucial role of vitamin D in the musculoskeletal system. Nutrients 2016;8. pii:E319.

[5] Rombaut L, Scheper M, De Wandele I, De Vries J, Meeus M, Malfait F, et al. Chronic pain in patients with the hypermobility type of Ehlers-Danlos syndrome: evidence for generalized hyperalgesia. Clin Rheumatol 2015;34:1121-9.

[6] Eller-Vainicher C, Bassotti A, Imeraj A, Cairoli E, Ulivieri FM, Cortini F, et al. Bone involvement in adult patients affected with Ehlers-Danlos syndrome. Osteoporosis Int 2016;27:2525-
31.

[7] Gulbahar S, Sahin E, Baydar M, Bircan C, Kizil R, Manisali $\mathrm{M}$, et al. Hypermobility syndrome increases the risk for low bone mass. Clin Rheumatol 2006;25:511-4.

[8] Scheper MC, de Vries JE, de Vos R, Verbunt J, Nollet F, Engelbert RH. Generalized joint hypermobility in professional dancers: a sign of talent or vulnerability? Rheumatology 2013;52:651-8.

[9] Kumar B, Lenert P. Joint hypermobility syndrome: recognizing a commonly overlooked cause of chronic pain. Am J Med 2017;130:640-7.

[10] Engelbert RH, Juul-Kristensen B, Pacey V, de Wandele I, Smeenk S, Woinarosky N, et al. The evidence-based rationale for physical therapy treatment of children, adolescents, and adults diagnosed with joint hypermobility syndrome/hypermobile Ehlers Danlos syndrome. Am J Med Genet C Semin Med Genet 2017;175:158-67.

[11] Joghee S, Dewan V, Chhabra A, Jahan A, Sharma N, Yadav TP. Vitamin D levels in children with idiopathic musculoskeletal pain. Int J Basic Appl Sci 2014;3:21-7.

[12] Juul-Kristensen B, Røgind H, Jensen DV, Remvig L. Interexaminer reproducibility of tests and criteria for generalized joint hypermobility and benign joint hypermobility syndrome. Rheumatology (Oxford) 2007;46:1835-41.

[13] Kasapoğlu Aksoy M, Altan L, Ökmen Metin B. The relationship between balance and vitamin $25(\mathrm{OH}) \mathrm{D}$ in fibromyalgia patients. Mod Rheumatol 2017;27:868-74.

[14] [cited 2018 20/03/2018]; Available from: https://mgm.gov.tr/veridegerlendirme/il-ve-ilceleristatistik.aspx?m=EDIRNE.

[15] Beighton P, Solomon L, Soskolne C. Articular mobility in an African population. Ann Rheum Dis 1973;32:413-8.

[16] Holick MF, Binkley NC, Bischoff-Ferrari HA, Gordon CM, Hanley DA, Heaney RP, et al. Evaluation, treatment, and prevention of vitamin D deficiency: an Endocrine Society clinical practice guideline. J Clin Endocrinol Metab 2011;96:1911-30.

[17] Parikh SJ, Edelman M, Uwaifo GI, Freedman RJ, SemegaJanneh M, Reynolds J, et al. The relationship between obesity and serum 1, 25-dihydroxy vitamin D concentrations in healthy adults. J Clin Endocrinol Metab 2004;89:1196-9.

[18] Karahan AY, Hüner B, Kuran B, Sezer N, Çelik C, Salbaş $\mathrm{E}$, et al. [Assessment of the relationship between vitamin D level and non-specific musculoskeletal system pain: a multicenter retrospective study (Stroke Study Group)]. Turk J Osteoporos 2017;23:61-6. [Article in Turkish]

[19] Holick M, Hossein-Nezhad A, Tabatabaei F. Multiple fractures in infants who have Ehlers-Danlos/hypermobility syndrome and or vitamin D deficiency: a case series of 72 infants whose parents were accused of child abuse and neglect. Dermatoendocrinol 2017;9:e1279768.

[20] Busch A, Hoffjan S, Bergmann F, Hartung B, Jung H, Hanel D, et al. Vascular type Ehlers-Danlos syndrome is associated with platelet dysfunction and low vitamin D serum concentration. Orphanet J Rare Dis 2016;11:111. 